\title{
GENERAL ASPECTS CONCERNING THE ORGANIZATION AND ASSURANCE OF CAMPAIGN SERVICES IN OPERATION
}

\author{
Sorin PÎNZARIU \\ sorinpinz@yahoo.com \\ “NICOLAE BĂLCESCU” LAND FORCES ACADEMY, SIBIU, ROMANIA
}

\begin{abstract}
The field of campaign services is currently the most complex area of logistical support, as it covers a wide range of services, requires cooperation between military bodies and various institutions, entities involved in providing them and requests promptness from planning and logistics management bodies in immediately solving the various problems that may arise. I set out to make an "radiography" of this complex field of logistics aiming to identify its general aspects in the processes of organization and assurance, as they manifest themselves at the level of a tactical unit
\end{abstract}

\section{KEYWORDS:}

Logistical support, campaign services, organization, insurance, tactical unit

\section{Introduction}

The success of an operation depends to a large extent on providing timely and efficient logistical support. Commanders are responsible for providing logistical support for the operation, distribution and efficient use of capabilities and resources. They must always consider the unit between operations and logistical support, being directly responsible for the integration of logistics into the operation.

Logistical support generates and sustains combat power throughout the range of operations, and by combining and achieving an optimal relationship between the mission and its logistical requirements, the foundations are laid for the conquest of the initiative, the maintenance of the pace and the exploitation of success.
In the operation, the provision of the necessary logistical support to the forces, in my view is carried out according to the following functional areas of logistics: supply and replenishment, movement and transport, maintenance, infrastructure, campaign services, contracting, Support of the Host Nation, RSOM and related fields. \section{services}

2. Conceptual aspects of campaign

As defined in the NATO Logistics Manual, the campaign services provided "... in support of combat forces or logistical activities include a wide range of services such as combat replenishment, map distribution, labour provision, postal and courier services, feeding, provision of facilities for laundry and bathing, funeral 
services, etc." (Logistics Capabilities Section, Defence Policy and Planning Division, Logistics, NATO HQ., 2012, p. 23).

These services may be provided by participating nations to both their own forces and to forces belonging to other NATO nations or multinational headquarters, and their effectiveness and effectiveness depends on close cooperation between the staff planning the operation, military logistics planners and civilian actors involved in the planning.

In accordance with NATO's logistics principles and policies, campaign services "... may include the provision of specialised labour, troop accommodation, underwear washing and bathing of the military, feeding, funeral services and other services such as map distribution, postal and courier services and equipment recovery" (NATO HQ., 2014, p. 17).

The national manual - logistical support of the Land Forces in NATO-led operations states that "the campaign services may include mortuary services, food preparation, replacement of individual equipment, bathing of the military, washing of linen and equipment, repairing of clothing and textiles, providing water and ensuring the living conditions of the military. Some nations have capabilities such as parachute, recovery and property transfer operations" (NATO, 2012, p. 82).

In my acceptance in the category of campaign services are included the following services: feeding and water insurance, bathing of herds, washing linen and cleaning equipment, postal and courier services, de-ratification and disinsection and funeral services.

\section{Organization of campaign services}

The process of management campaign services is cyclical in nature, starting with the establishment of the mission, continuing with the specification of the objectives over a certain period, setting the tasks for each structure involved in the performance of the mission and ending with the analysis of their achievement and the evaluation of the final results. In this process, certain phased, called management functions are carried out in a logical sequence.

With regard to the functions of the management of the campaign services, they can be defined as the set of relatively independent actions, which are followed in a certain order over time and which are carried out by a management system which exerts influence strips on the execution system, with a view to establishing the tasks and carrying them out.

The organization is intended to indicate "how to make" a structure in order to achieve its objectives. As a function of management, the organization can be defined as all the actions taken to determine and group the activities necessary to achieve the proposed objective, under the conditions of the maximum efficient use of the resources available.

Next, I propose to address the issue of organizing and providing campaign services at the level of a tactical unit, detailing more important general theoretical aspects for each service.

According to the definition provided by the Explanatory Dictionary of the Romanian language, the action to organize is aimed at "making a social group, an institution, etc. function or act organically (allocating tasks and coordinating them according to an appropriate plan); establish and coordinate the technical, economic, administrative means so as to allow the optimal execution of a process" (Romanian Academy, Institute of Linguistics "Iorgu Iordan - Al. Rosetti", 2009, p. 764).

In the military sense of the term, the organization of logistical support involves the transmission of missions to subordinates and the implementation of measures leading to the fulfillment of the provisions of the logistic support plan. This organizational process is usually carried out after the validation of the logistic support plan, but, when the short time available requires, 
certain organizational measures may be adopted in parallel with the planning process of the logistic support

From the perspective of providing campaign services, "organizing ... involves actions taken to make efficient use of specific resources, to determine, enumerate and group activities to achieve the objectives of each campaign service, i.e. to link the efforts of the logistical support bodies to achieve the intended purpose" (Zisu, 2012, p. 195).

On the basis of the above definitions, we are of the opinion that the organization, from the point of view of providing campaign services, takes into account the activities carried out by the management structures to identify, establish and share the specific tasks of each campaign service to the execution structures, so that their actions support the tasks of the tactical unit in the most effective way.

The organization of logistic and implicit support of the campaign services, at the level of the tactical unit, is carried out on the basis of the Logistic Support Order / Logistic Support Annex to the Operation Order of the upper echelon, and the assurance is carried out by the logistics forces in the composition of the unit on the basis of the commander's decision.

By providing the campaign services timely and smoothly, the unit's logistical support structures contribute significantly to ensuring the necessary conditions for the fighting structures to carry out the missions they have been in.

\section{General aspects related to the provision of campaign services in support of the tactical units}

As a general concept of providing logistical support, in NATO-led operations, while each nation assumes responsibility for providing the necessary logistical support to its own forces, as a rule, to operations carried out outside the national territory, campaign services can be provided both by their own forces (with the support of economic operators and international contractors available in the operation area) and with multinational support. Multinational support can be provided through the leading nation, through the specialized nation, through mutual support/cooperation agreements between participating nations or through the support of the Host Nation, where these options are available and are considered more advantageous. The support of the Host Nation and contractors shall be provided in particular in the rear areas of the area of operations, outside the areas where the own military is on contact.

For the conduct of offensive operations, the provision of campaign services is based on the anticipated support needs of each subordinate structure. Campaigns services will be integrated into the tactical unit maneuvering scheme to ensure synchronization of operations and to avoid interference with likely or planned maneuvering actions. Specific activities carried out to provide campaign services will, as far as possible, be carried out in hidden, masked (natural or artificial) locations. Decision points will be planned to activate or disable collection points based on the movements or actions planned by the unit For the prompt provision of campaign services, the personnel involved will be continuously aware of the missions and disposal locations of the structures / subunits and technical means providing these services. Specific equipment of other weapons (genius or CBRN) may be used to substitute equipment necessary to provide campaign services (bathing, linen washing, etc.) in order to reduce the logistical footprint of the structures participating in the operation. During the execution of the offensive operations some of the campaign services are temporarily suspended, ensuring during the preparation or after the completion of the operation. Exceptions are funeral services, which are given particular attention as a result of the higher losses estimated for this type of operation. 
During the operation of the defense, it will be avoided to establish logistical supports paternal (models) (by planning activities carried out on different days, at different times), in order to reduce the vulnerability of logistic structures to the actions of the enemy. Routine logistics activities will also be planned to take place at night or during periods of time with low visibility.

Logistical structures shall be arranged in the area of operations in locations positioned as far back as possible, but at a distance to ensure adequate support for maneuvering units. They shall also be avoided in enemy aviation flight lanes, in areas vulnerable to artillery attack or CBRN attack. This requires coordination of the S-4 Logistics module with the S-2 Information and S-3 Operations modules, which control the maneuvers, in order for the logistics maneuver to be integrated into the brigade's maneuvering plans.

Periodically, generally every 72 hours, based on the known threat level, it is necessary to move the structures that provide the campaign services in order to reduce their vulnerability to detection. The use of coatings, natural masking, dispersion and protection provided by the land (trees, ditches, other natural forms of camouflage) will be maximized. Also, the military in the logistics structures or contractors will not discuss with the locals about the future movements of the logistics structures.

In order to ensure the campaign services necessary for the operation of the defense, it is necessary to cooperate with the engineering structures for logistics for the preparation of the locations of the feeding, bathing and washing structures of the linen (drain channels, household water discharge, concrete platforms for the location of logistics equipment, etc.) and for the provision of water (digging wells).

In the case of stability operations, the campaign services provided by military structures are widely used in the initial phase. Subsequently, the footprint of military logistics structures is reduced, depending on the possibilities offered by the area where the operation is carried out, with campaign services transiting to civilian contractors or Host Nation Support (HNS). During these operations, joint, multinational or inter-agency support requirements may arise. As a particularity, it will be borne in mind that logistical assistance to one party may affect relations with the other parties involved.

In support operations, as in stability operations, campaign services provided by specialized military structures are used predominantly at the beginning of the operation. The transition of these services by civilian contractors depends on the duration of the operation. Logistical support requirements may arise at the meeting level or interagency during these operations.

In multinational operations, logistics actions to provide the necessary campaign services for combat forces as well as combat support are aimed at actions such as local contracting or Host Nation Support. The aim is thus to reduce the costs of moving staff or specialized economic operators from the countries of origin of the structures participating in the operation to the theatres of operations by recruiting locally the workforce capable of providing certain campaign services.

In allied operations, NATO and participating nations are responsible for providing campaign services to support operations. This collective responsibility should encourage the establishment and sharing of cooperation-based capabilities and logistical resources in order to effectively support the multinational force. However, each nation ultimately has the responsibility of securing logistical resources for its own forces.

In terms of providing campaign services in multinational stability and support operations led by the Alliance, member nations and NATO (due to common responsibilities) have agreed that 
they should be provided either individually or through memoranda, technical agreements or mutual agreements.

\section{Conclusions}

Depending on the type of operation in which the tactical unit participates and other factors that may influence the provision of campaign services (climate, environmental conditions in which the operation is carried out), some of the services may become more important than others. For example, when operating in a desert climate environment, providing military bathing or washing facilities for individual equipment can become a priority for the commander of the force.

However, although military theorists have attempted to rank the campaign services, the experience gained in the operations carried out by the structures of the Romanian Army outside the national territory has shown that these services cannot be ranked in terms of importance, each of which has due importance in maintaining a high morale of the troops.

\section{REFERENCES}

Logistics Capabilities Section, Defence Policy and Planning Division, Logistics, NATO HQ. (2012). NATO Logistics Handbook. Brussels: Author.

NATO. (2012). F.T./L - 1 Handbook of Logistical Support of The Land Forces in NATO-led operations. $2^{\text {nd }}$ Edition, art. 239, Bucharest.

NATO HQ. (2014). MC 0319/3, NATO Principles and Policies for Logistics. Brussels: Author.

Romanian Academy, Institute of Linguistics "Iorgu Iordan - A1. Rosetti”. (2009). DEX - Dictionarul explicativ al limbii române. Bucharest: Univers Enciclopedic.

Zisu, M.A. (2012). Campaign Services in Stability and Support Operations. PhD Thesis, Bucharest: Editura Universității Naționale de Apărare "Carol I". 